\title{
Permanganate Oxidation of Microcystin-LA: Kinetics, Quantification, and Implications for Effective Drinking Water Treatment
}

\author{
David C. Szlag $\mathbb{D}^{1},{ }^{1}$ Brian Spies, ${ }^{1}$ Regina G. Szlag, ${ }^{2}$ and Judy A. Westrick ${ }^{2}$ \\ ${ }^{1}$ Department of Chemistry, Oakland University, Rochester, MI 48309, USA \\ ${ }^{2}$ Department of Chemistry, Wayne State University, Detroit, MI 48202, USA
}

Correspondence should be addressed to David C. Szlag; szlag@oakland.edu

Received 22 October 2018; Accepted 17 March 2019; Published 28 May 2019

Academic Editor: Valerio Matozzo

Copyright (C) 2019 David C. Szlag et al. This is an open access article distributed under the Creative Commons Attribution License, which permits unrestricted use, distribution, and reproduction in any medium, provided the original work is properly cited.

\begin{abstract}
Permanganate pretreatment of drinking water is effective in transforming dissolved, noxious contaminants and in reducing halogenated by-products. Permanganate targets specific compounds such as taste and odor compounds, disinfection precursors, manganese, and natural organic contaminants that are not removed readily by conventional treatment alone. Cyanobacterial blooms (cHABs) can increase disinfection by-product precursors as well as the cyanotoxin, microcystin (MC), a potent liver toxin. MC toxicity is conferred by a unique, conserved amino acid, Adda, that inhibits protein phosphatase 1 and $2 \mathrm{~A}$. Although over 150 $\mathrm{MC}$ congeners have been reported, thousands of MCs are statistically possible. Over the last ten years, one congener, MC-LA, has been reported with increasing frequency, making it one of the most common cyanotoxins identified in North American freshwater systems; yet its oxidation has not been widely studied. Frequently, Adda specific enzyme-linked immunosorbent assay (ELISA) and protein phosphatase inhibition assay (PPIA) are used to quantitate total MCs to evaluate treatment efficiency and exposure. Anecdotal reports suggest that MC degradation products can cause interference with the Adda-ELISA. MC-LA was used as the model MC compound in this study. PPIA quantitation of MC-LA in water agreed with liquid chromatography high resolution mass spectrometry (LC/HRMS), whereas the ELISA quantitation did not agree with LC/HRMS quantitation. We determined the second order rate constant for MC-LA as $118 \pm 9 \mathrm{M}^{-1} \mathrm{~s}^{-1}$, the activation energy to be $21.2 \mathrm{~kJ} \mathrm{~mol}^{-1}$, and the rate to be independent of $\mathrm{pH}$ between $\mathrm{pH} 6$ and 9. Ten oxidation products (OPs) were observed by LC/HRMS and three primary reaction pathways are proposed. The reaction pathways were used to explain differences in the quantification by Adda-ELISA, HRMS, and PPIA. The oxohydroxylation of MC-LA produced two major OPs, $\mathrm{C}_{46} \mathrm{H}_{67} \mathrm{~N}_{7} \mathrm{O}_{14}[\mathrm{M}+\mathrm{H}]^{+}=942.4819$ and $\mathrm{C}_{46} \mathrm{H}_{69} \mathrm{~N}_{7} \mathrm{O}_{15}[\mathrm{M}+\mathrm{H}]^{+}=960.4925$. Major OPs may contain an unmodified Adda and are the likely cause of interference with the Adda-ELISA. Several governmental agencies recommend the use of the Adda-ELISA to determine the MC quantitation for treatment efficiency and customer exposure; yet our results suggest that these or other OPs interfere with the Adda-ELISA causing artificially high values for total MCs.
\end{abstract}

\section{Introduction}

The severity and frequency of cyanobacteria blooms are increasing due to a combination of factors including increased nitrogen and phosphorous pollution, climate change, and altered system ecology which in some cases may be the result of invasive species $[1,2]$. Cyanobacteria blooms impact drinking water treatment efficiency by increasing chemical demand and particulate load, resulting in increased risk of pathogen and cyanotoxin breakthrough [3, 4]. Microcystins (MCs) are the most common class of cyanotoxins. During log-growth phase of the bloom, approximately $90 \%$ of the microcystin is intracellular and $10 \%$ is extracellular. Most treatment processes have specific targeted efficiencies for particulate and/or contaminant removal; to remove MCs, both types of processes must be optimized. Quantitative tools used to monitor MC drinking water treatment removal efficiency and exposure are critical for consumer safety. Ideally, these tools, i.e., assays, would determine the concentration of MCs as well as the toxicity of the water and would be simple enough to be performed at the treatment plant. Our goal was to vet the use of two commercial MC assays to quantitate MCs 


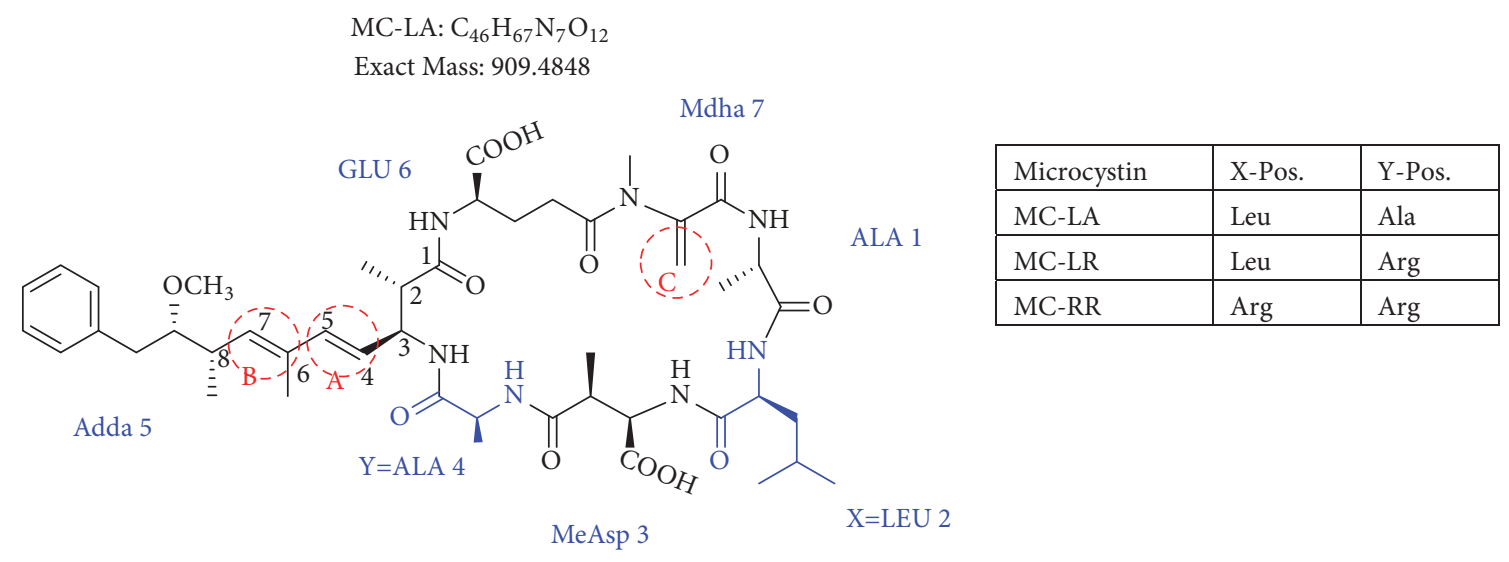

FIGURE 1: General structure of MC-LA showing variable amino acid positions and the primary (alkene) sites subject to permanganate oxidation.

during permanganate oxidation and compare their results to the quantitation of MCs by LC/HRMS. Our hypothesis was that the quantitation by Adda-ELISA, PPIA, and LC/HRMS would agree.

MCs are cyclic heptapeptides of varying amino acid composition with respect to two positions (" $\mathrm{X}$ " and " $\mathrm{Y}$ ") that contain variable L-amino acids as shown in Figure 1. MCs are comprised of three D-amino acids: alanine (Ala), methylaspartic acid (MeAsp), and glutamic acid (Glu) (Figure 1). The structure also includes two unique amino acids: N-methyldehydroalanine (Mdha) and 3-amino-9methoxy-2,6, 8-trimethyl-10-phenyldeca-4(E),6(E)-dienoic acid (Adda) (Figure 1). The amino acid Adda is found in position 5 of the peptide ring in all MCs, and it is this moiety that is responsible for the toxicity. The MCs inhibit irreversibly protein phosphatase 1 (PP1) and protein phosphatase 2A (PP2A) and act as hepatotoxins because they are preferentially transported into liver cells. The toxicity of the various congeners varies by two orders of magnitude with MC-LR and MC-LA noted as the most toxic [5]. MC-LA is prevalent in several regional water sources, but has not been reported historically as widely as MC-LR [6]. Not many comprehensive oxidative treatment studies have investigated the oxidation of MC-LA, even though it has been determined to have one of the slowest oxidation rates with the most widely used oxidant, chlorine [7].

The primary mode of human MC exposure is through drinking water. Historically, conventional water treatment facilities have been able to meet the World Health Organization (WHO) guidance value of $1.0 \mu \mathrm{g} / \mathrm{L}$ MC-LR [8]. The US EPA has expanded monitoring from a single congener, MC$\mathrm{LR}$, to encompass all MC congeners referred to as total MCs. In 2015 US EPA released a two-tier drinking water health advisory (HA) based on age: preschool at $0.3 \mu \mathrm{g} / \mathrm{L}$ total MCs, and above preschool age at $1.6 \mu \mathrm{g} / \mathrm{L}$ total MCs [9]. Infant and toddlers ingest 5 times more liquid to body mass than schoolage children and adults, hence, the decrease from $1.6 \mu \mathrm{g} / \mathrm{L}$ for school-aged children and adults to $0.3 \mu \mathrm{g} / \mathrm{L}$ total MCs for preschool-aged children. More countries will likely post similar guidance. Consequently, the drinking water industry is tasked to determine the total concentration of a class of compounds containing many congeners at the sub-part-perbillion concentration, a challenging task. Understanding the variability in oxidation kinetics of MCs and the oxidation pathways is needed, so that drinking water treatment can be optimized for MC removal and to minimize toxic OPs. Interferences must be identified and quantified to ensure accurate process monitoring.

Two classes of commercial biochemical assays, ELISA [10] and PPIA [11], have become standard technologies to quantitate total MCs for drinking water utilities. These kits may use different antibodies or enzymes, but generally respond to all MC congeners, albeit variably. Several governmental agencies recommend the use of the Adda-ELISA in the mistaken notion that Adda alone confers toxicity. To date, Adda-ELISA quantitation has not been directly correlated to MC toxicity. The PPIA method is based on the enzymes which the MCs inhibit, and its quantitative response has been correlated to toxicity. Some studies have observed that the total MC concentrations derived from ELISA and PPIA are often higher than the total MC concentration derived from LC/MS [12-14]. Specifically, after chemical oxidation treatment, the Adda-ELISA total MC concentration has been reported to be higher than that reported by $\operatorname{LC} / \mathrm{MS}[15,16]$. There is a need to determine which OPs are causing a response with the Adda-ELISA or PPIA and what their relative concentrations are under different reaction conditions.

Often permanganate is added at the source water intake. Anoxic source water may contain metals in a reduced state, and the initial permanganate demand comes from their oxidation. Oxidative pretreatment of water using permanganate is employed commonly to oxidize nuisance natural contaminants such as taste and odor compounds. Permanganate will selectively oxidize alkenes, and arguably does not rupture cells and release MCs at normal treatment dosages and contact times as determined by LC/MS [17-19]. In the early literature, the basic permanganate mechanism was believed to be the production of vicinal dihydroxyl or carbonyl products [20]. More recent work by Kim et al. [21] describes the permanganate oxidation progressing through vicinal hydroxyl-carbonyl pathways more like ozone oxidation $[22,23]$ rather than vicinal dihydroxy OPs produced via 
chlorine oxidation [24]. Because of its selective oxidation, permanganate treatment may be useful early in the treatment process for degradation of MCs as part of a multibarrier oxidation process to achieve the new low concentration guidance for total MCs.

To date, three drinking water utilities in United States have posted "do not drink" advisories because of MCs detected in their finished drinking water. Carroll Township, OH (2013); Toledo, OH (2014); and Salem, OR (2018) reported MCs concentrations above $1.0 \mu \mathrm{g} / \mathrm{L}$ total MC. Because they serve 400,000+ residents, the Toledo, $\mathrm{OH}$, advisory was the most publicized. The finished drinking water was reported to be above $1.0 \mathrm{ug} / \mathrm{L}$ total MCs as measured by Adda-ELISA, but these results were not validated by LC/MS/MS. Since "do not drink" advisories result in financial loss for businesses and loss of consumer confidence in the local water authority, identifying potential interferences in analytical methods that result in false positives is as critical as identifying potentially toxic OPs.

Source water MC concentrations often exceed $1 \mu \mathrm{g} / \mathrm{L}$, and it is not unusual for concentrations to range from 5 to $20 \mu \mathrm{g} / \mathrm{L}$ total MCs. Our research focuses on how permanganate can be used as an effective treatment barrier and on quantification of MCs after treatment. In order to determine permanganate efficiency, we determine how congener chemical variation impacts oxidation rates; how the cyanobacteria cell is impacted by permanganate oxidation; and how variations in source water quality $(\mathrm{pH}$ and natural organic compound) affect permanganate oxidation. On-site quantitation is essential for monitoring the treatment process. We evaluated the Adda-ELISA and PPIA on-site methods by comparing the purported rate constants and by determining the oxidation reaction mechanism and pathways by LC/HRMS. Furthermore, determining the oxidation pathway provides insight regarding residual toxicity of OPs.

\section{Materials and Methods}

2.1. Microcystins. To compare our procedures to other researchers, MC-LR, -LA, and -RR were purchased from Enzo Life Sciences, Inc. For the majority of the oxidation experiments, however, MC-LA was purified from a Microcystis bloom/scum harvested from Upper Klamath Lake, OR, in 2015. MCs were released from the cells by three freeze/thaw cycles. Lysate was centrifuged in a swinging bucket then vacuum filtered through a $47 \mathrm{~mm} 0.4 \mu \mathrm{m}$ glass fibre filter. A crude extract was made by passing the lysate through a $60 \mathrm{~cm}^{3} \mathrm{C} 18$ solid phase extraction column (Thermo Fisher Scientific, USA), discarding the effluent, and making the crude extract by eluting the bound material with $100 \%$ HPLC grade methanol. MC-LA was separated from the crude extract by high performance liquid chromatography with a photodiode array detector using a $\mathrm{C} 18$ semipreparative column (Atlantis dC18 OBD Prep Column, 100A $5 \mu \mathrm{m} 10 \mathrm{~mm}$ x $100 \mathrm{~mm}$ column, Waters Corp.). MC-LA was separated based on retention time and by UV spectrum. The MC-LA was validated by high resolution mass spectrometry (HRMS). Concentrated MC stock solutions were prepared at $0.5 \mathrm{mg} / \mathrm{ml}$ in MS grade methanol. Beer's Law with a molar extinction coefficient of $39,800 \mathrm{~L} \cdot \mathrm{mol}^{-1} \cdot \mathrm{cm}^{-1}$ was used to determine the actual concentration of the MC-LA stock solution prior to dilution for the batch experiments [25].

A four-place mini jar test apparatus was used for all laboratory experiments with the paddle mixer set at $50 \mathrm{rpm}$. A $200 \mathrm{~mL}$ sample of DI, buffered (ammonium carbonate), or lake water was dispensed into each reaction chamber of the mini-mixer. The jar test unit was placed in a temperaturecontrolled cabinet to obtain the desired temperature 30 minutes prior to the start of batch experiments to reach thermal equilibrium. An intermediate stock solution of MC was prepared in DI water from the standardized stock. The MC stock solution was pipetted into the reaction chamber to obtain an initial concentration of $50 \mu \mathrm{g} \mathrm{MC} / \mathrm{L}$ for kinetic tests. Prior to the start of the experiment, $10 \mathrm{uL}$ of $0.05 \mathrm{M}$ sodium thiosulfate was preloaded into $1.4 \mathrm{~mL}$ conical microfuge tubes that would receive samples to minimize delays in quenching the reaction. Prior to the addition of permanganate, a control sample of $1.0 \mathrm{~mL}$ was taken from each chamber $(t=0$ seconds). Stock permanganate solution was added to the reaction chamber to bring the concentration to the desired $2.0 \mathrm{mg} / \mathrm{L} \mathrm{MnO}_{4}{ }^{-}$, and $1.0 \mathrm{~mL}$ aliquots were collected at specified time intervals into the tubes preloaded with sodium thiosulfate. Generally, the kinetic studies of MC-LA were performed at six time points: $0,2,4,6,20$, and 40 minutes. Temperatures for the Arrhenius plot were 4, 10, 18, 25, 30 , and $35^{\circ} \mathrm{C}$. Two temperatures, 25 and $35^{\circ} \mathrm{C}$, were run for the experiments in which all three methods, AddaELISA, PPIA, and LC/HRMS, were used to quantitate MCs. These samples were immediately capped and vortexed for 6-10 seconds. Samples were held on ice for the duration of the batch experiment, then stored at $4^{\circ} \mathrm{C}$, and analyzed within 48 hours. Prior to analysis by LC/TOF, PPIA, or ELISA, samples were centrifuged in a microfuge to pellet $\mathrm{MnO}_{2}$.

The sodium thiosulfate quenching solution was prepared by dissolving $3.01 \mathrm{~g}$ of sodium thiosulfate in $25 \mathrm{~mL}$ of $18 \mathrm{M}^{-} \Omega$ deionized water. This stock solution was stored in an airtight, amber bottle away from light. The stock solution was diluted 1:10 as needed for experiments.

The enzyme-linked immunosorbent assays (ELISA) were purchased from Abraxis, Inc. Calibration curves for MCs were quantitated using the response curve of MC-LR using standards: $0,0.15,0.5,1.0,2.5$, and $5.0 \mu \mathrm{g} / \mathrm{L}$. All samples were diluted 20 -fold to bring them into the range of the standard curve. All samples and standards were run in duplicate. Plates were quantified using a BioTek Synergy H1M microplate reader. A four-parameter curve fit was performed using BioTek Gen5 software.

Protein Phosphatase Inhibition Assay (PPIA) was developed by Zeulab S.L. Zaragoza, Spain, and distributed in the USA by Abraxis, Inc. Calibration curves for MCs range from $0.25-2.5 \mu \mathrm{g} / \mathrm{L}$. All samples were diluted 20 -fold to bring them within the range of the standard curve. This test is based on inhibition of protein phosphatase 2A. All samples and standards were run in duplicate. Calibration curves for MCs were quantitated using the response curve of MC-LR. A fourparameter curve fit was performed using the BioTek Gen5 software. 
TABLE 1: Summary of second order rate constants for MCs.

\begin{tabular}{|c|c|c|c|c|c|}
\hline MC-LA & MC-LR & MC-RR & Temp. & $\mathrm{pH}$ & Reference \\
\hline $\mathrm{k}\left(\mathrm{M}^{-1} \mathrm{~s}^{-1}\right)$ & $\mathrm{k}\left(\mathrm{M}^{-1} \mathrm{~s}^{-1}\right)$ & $\mathrm{k}\left(\mathrm{M}^{-1} \mathrm{~s}^{-1}\right)$ & ${ }^{\circ} \mathrm{C}$ & & \\
\hline $118 \pm 9$ & $320 \pm 20$ & $467(\mathrm{~N}=1)$ & $18 \pm 1$ & $6.8 \pm 0.2$ & This study \\
\hline $160 \pm 1.3$ & $386 \pm 20$ & $520 \pm 9$ & $21 \pm 1$ & 7.2 & Kim et al. [21] \\
\hline \multirow[t]{4}{*}{170} & 408 & & $23 \pm 1$ & 7.6 & Ding et al. [26] \\
\hline & 290 & & $23 \pm 1$ & 7 & Jeong et al. [20] \\
\hline & $357 \pm 18$ & 418 & 20 & 7.2 & Rodríguez et al. [27] \\
\hline & & $469 \pm 37$ & 25 & 6.7 & Chen et al. [28] \\
\hline
\end{tabular}

LC/MS analysis was performed by HPLC (Agilent 1200) with a ZORBAX Eclipse Plus C18 (i.d. $2.1 \times 50 \mathrm{~mm}$, $1.8 \mathrm{~mm}$ ) using gradient (10-100\%) conditions with $0.1 \%$ formic acid and acetonitrile (flow rate: $0.4 \mathrm{~mL} \mathrm{~min}^{-1}$ ). An Agilent 6520 quadrupole-time-of-flight (Q-TOF) was used for identification and quantitation. MS conditions were as follows: ionization, ESI; nebulizer, $50 \mathrm{psi}\left(\mathrm{N}_{2}\right)$; drying gas, 10 $\mathrm{L} \min ^{-1}, 350^{\circ} \mathrm{C}\left(\mathrm{N}_{2}\right)$; Vcap, $5000 \mathrm{~V}$; fragmentor, $100 \mathrm{~V}$; scan, $\mathrm{m} / z$ 100-1500; 10,000 transients/scan, 10,000; references, $\mathrm{m} / z$ 121.0509 and 922.0098; and collision energy, 15-30 eV.

2.2. Pseudo-First-Order Kinetic Analysis. The oxidation reaction rate of MC-LA by $\mathrm{MnO}_{4}{ }^{-}$can be expressed as

$$
\mathrm{r}=\mathrm{k}[\mathrm{MC}-\mathrm{LA}]^{\mathrm{x}}\left[\mathrm{MnO}_{4}^{-}\right]^{\mathrm{y}}
$$

where $\mathrm{r}$ is the reaction rate, $\mathrm{k}$ is the rate constant, [MC-LA] and $\left[\mathrm{MnO}_{4}{ }^{-}\right]$are concentrations, and $\mathrm{x}$ and $\mathrm{y}$ are the reaction orders with respect to MC-LA and $\mathrm{MnO}_{4}{ }^{-}$, respectively [28]. When the concentration of $\mathrm{MnO}_{4}{ }^{-}$is excessive, (1) can be simplified to (2) and (3):

$$
\mathrm{r}=\mathrm{k}^{\prime}[\mathrm{MC}]^{\mathrm{x}}
$$

where the product of the 2nd order rate constant and permanganate concentration is effectively constant and $\mathrm{k}^{\prime}$ is known as a pseudo-first-order rate constant.

$$
\mathrm{k}^{\prime}=\mathrm{k}\left[\mathrm{MnO}_{4}^{-}\right]^{\mathrm{y}}
$$

This allows the use of the first-order integrated rate law and the determination of a pseudo-first-order rate constant $\mathrm{k}^{\prime}$.

$$
\ln \left(\frac{M C}{M C o}\right)=-k^{\prime} t
$$

The natural log of the ratio, MC concentration divided by the initial MC concentration, was plotted versus time. The slope of this line is equal to the pseudo-first-order rate constant. The concentration of permanganate is present in 20-fold excess relative to the MC-LA and its concentration is effectively unchanged over the 40 -minute experiment. The second order rate constant is calculated by dividing $\mathrm{k}^{\prime}$ by the molar concentration of permanganate.

\section{Results and Discussion}

3.1. Oxidation Kinetics of MC-LA with Permanganate. Chemical oxidation is considered an excellent drinking water treatment barrier for MC, such that America Water Work Association has a web-based modeling program to assist drinking water management to estimate the efficiencies of oxidation removal by chlorine, permanganate, and ozone [29]. This program uses published kinetics, $\mathrm{pH}$ dependent kinetics, and activation energies (temperature dependent kinetics) in their predictive empirical model. The authors of this tool have identified four reoccurring problems: (1) only a limited number of MCs have been investigated; (2) often temperature and $\mathrm{pH}$ dependent experiments are not performed; (3) the impact of NOM and cyanobacteria cells on oxidation kinetics is highly variable; and (4) kinetics determined by LC/MS are different from kinetics determined by Adda-ELISA. Our investigation provided temperature and $\mathrm{pH}$ dependence data on a less examined MC (MC-LA). By using Adda-ELISA, PPIA, and LC/HRMS to measure MC concentrations, we are able to show that OPs were likely binding to the Adda-ELISA antibody. Finally, elucidation of the reaction mechanism by LC/HRMS gives insight as to which potential OP products interfere with Adda-ELISA.

We observed second order rate constants $120 \pm 9 \mathrm{M}^{-1}$. $\mathrm{s}^{-1}$ and $114 \pm 8 \mathrm{M}^{-1} \cdot \mathrm{s}^{-1}$ for our purified and commercially available MC-LA, respectively, with 2.0 ppm $\mathrm{MnO}_{4}{ }^{-}$, at $\mathrm{pH}$ 6.8 , and $18 \pm 1^{\circ} \mathrm{C}$. Combining experiments $(\mathrm{N}=9)$ yielded an average second order rate constant at these conditions of $118 \pm$ $9 \mathrm{M}^{-1} \cdot \mathrm{s}^{-1}$. This is approximately $25 \%$ lower than previously reported values by Kim et al. [21] and Ding et al. [26]. We also conducted a limited number of experiments with MCRR and MC-LR. Our rate constant values for MC-LR and $\mathrm{MC}-\mathrm{RR}$ are consistent and in the range observed by other researchers and follow the trend MC-RR > MC-LR > MC-LA (Table 1). Correcting for the temperature difference between our conditions and those reported by Kim et al. [21] or Ding et al. [26] would increase our values by eight percent. Sample data are shown in Figure 2.

The activation energy $\left(\mathrm{E}_{\mathrm{a}}\right)$ was determined by taking the natural $\log$ of the Arrhenius equation and plotting $\ln \mathrm{k}$ versus $1 / \mathrm{T}$ (Figure 3 ). The coefficient of determination $\left(\mathrm{R}^{2}\right)$ for the values in this study $(\mathrm{N}=24)$ over the temperature range $4^{\circ} \mathrm{C}$ to $35^{\circ} \mathrm{C}$ was 0.85 . The $\mathrm{E}_{\mathrm{a}}$ was $21.2 \pm 1.9 \mathrm{~kJ} \mathrm{~mol}^{-1}, \mathrm{pH}$ was $6.7 \pm$ 0.2 , and the preexponential factor was $577,962 \mathrm{M}^{-1} \mathrm{~s}^{-1}$. This $\mathrm{E}_{\mathrm{a}}$ value for MC-LA is comparable to the value $21.5 \pm 0.6 \mathrm{~kJ}$ $\mathrm{mol}^{-1}$ reported by Kim et al. [21].

We investigated the effect of $\mathrm{pH}$ on the rate constant over the range from $\mathrm{pH} 6$ to $\mathrm{pH} 9.5$ (Figure 4) and found that $\mathrm{pH}$ has a negligible effect on $\mathrm{k}$ between $\mathrm{pH} 6$ and 8.5 but 


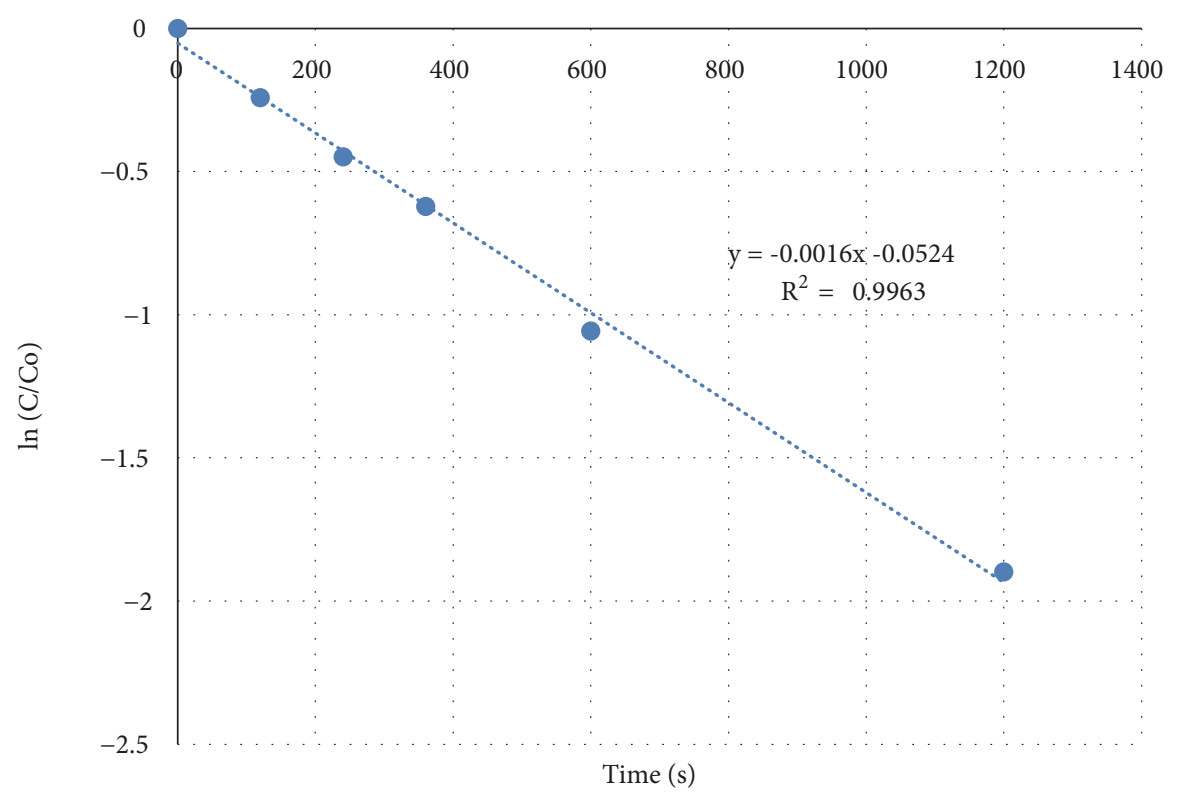

FIGURE 2: Example MC-LA pseudo-first-order oxidation with 2.0 ppm permanganate.

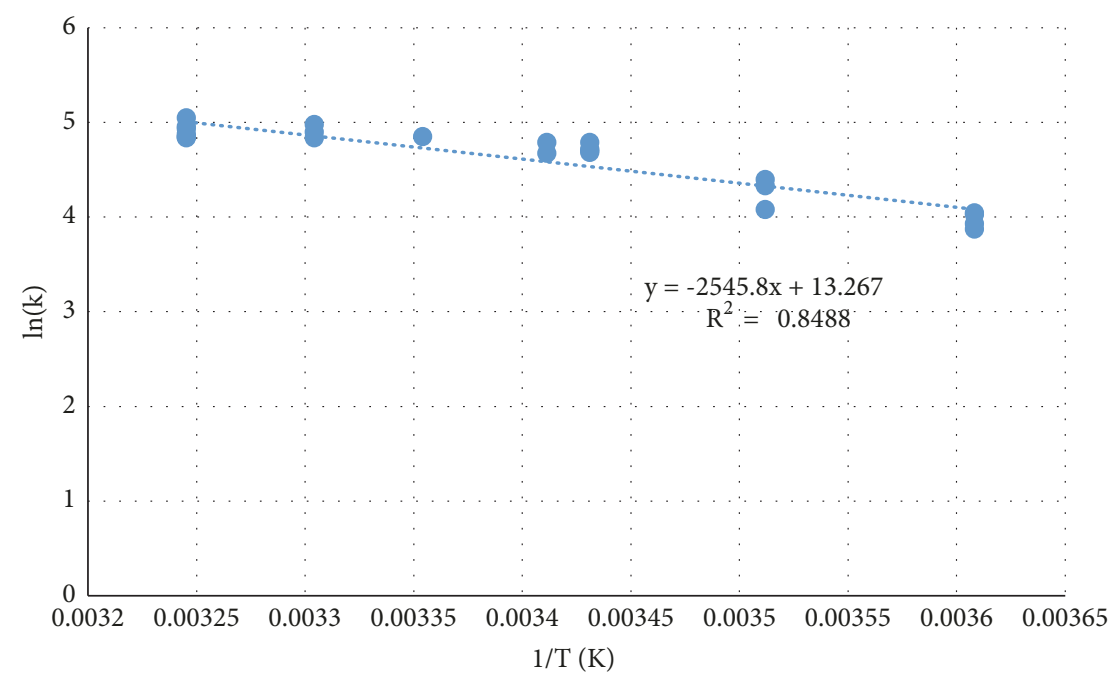

Figure 3: Arrhenius plot for MC-LA over the temperature range $4^{\circ} \mathrm{C}$ to $35^{\circ} \mathrm{C}$.

appears to drop off at $\mathrm{pH}$ 9.5. Often $\mathrm{pH}$ of the water during a bloom is $>8.5$, and the reduction of oxidation rate will reduce treatment efficiency.

Many groups have studied the effects of NOM and the type of NOM that reacts with permanganate. Jeong et al. [21] show that fulvic and humic acids react with permanganate, while polysaccharides and proteins are much less reactive. The effect of Lake Erie water (Table 2) was evaluated on the reaction of permanganate and MC-LA. Within experimental error there was no effect on the rate constant at $22^{\circ} \mathrm{C}$ and $35^{\circ} \mathrm{C}$. We did not completely characterize the NOM in the lake water, but the Lake Erie water is low in humic and fulvic acids and higher in proteinaceous NOM [30]. Permanganate reacts more slowly with proteins or amino acids relative to alkenes.

We further support this observation with experiments containing Microcystis cells (M. viridis) as shown in Table 3.
TABLE 2: Effect of natural lake water on the MC-LA second order rate constant.

\begin{tabular}{lcc}
\hline Source & $22^{\circ} \mathrm{C}$ & $35^{\circ} \mathrm{C}$ \\
\hline Filtered Lake Water & $118 \pm 15 \mathrm{M}^{-1} \mathrm{sec}^{-1}$ & $144.5 \mathrm{M}^{-1} \mathrm{sec}^{-1}$ \\
\hline DI & $113.5 \pm 6.5 \mathrm{M}^{-1} \mathrm{sec}^{-1}$ & $138.5 \pm 12.5 \mathrm{M}^{-1} \mathrm{sec}^{-1}$ \\
\hline
\end{tabular}

TABLE 3: The variation of the MC-LA second order rate constant in the presence of $M$. viridis cells.

\begin{tabular}{lccc}
\hline 0 cells $/ \mathrm{mL}$ & 31,000 cells $/ \mathrm{mL}$ & 160,000 cells $/ \mathrm{mL}$ & 160,000 lysed \\
\hline $114.5 \mathrm{M}^{-1} \mathrm{sec}^{-1}$ & $122 \mathrm{M}^{-1} \mathrm{sec}^{-1}$ & $114.3 \mathrm{M}^{-1} \mathrm{sec}^{-1}$ & $128 \mathrm{M}^{-1} \mathrm{sec}^{-1}$ \\
\hline
\end{tabular}

There is no statistical change in the $\mathrm{k}$ value as the amount of cyanobacteria cells is increased. Furthermore, there is no 


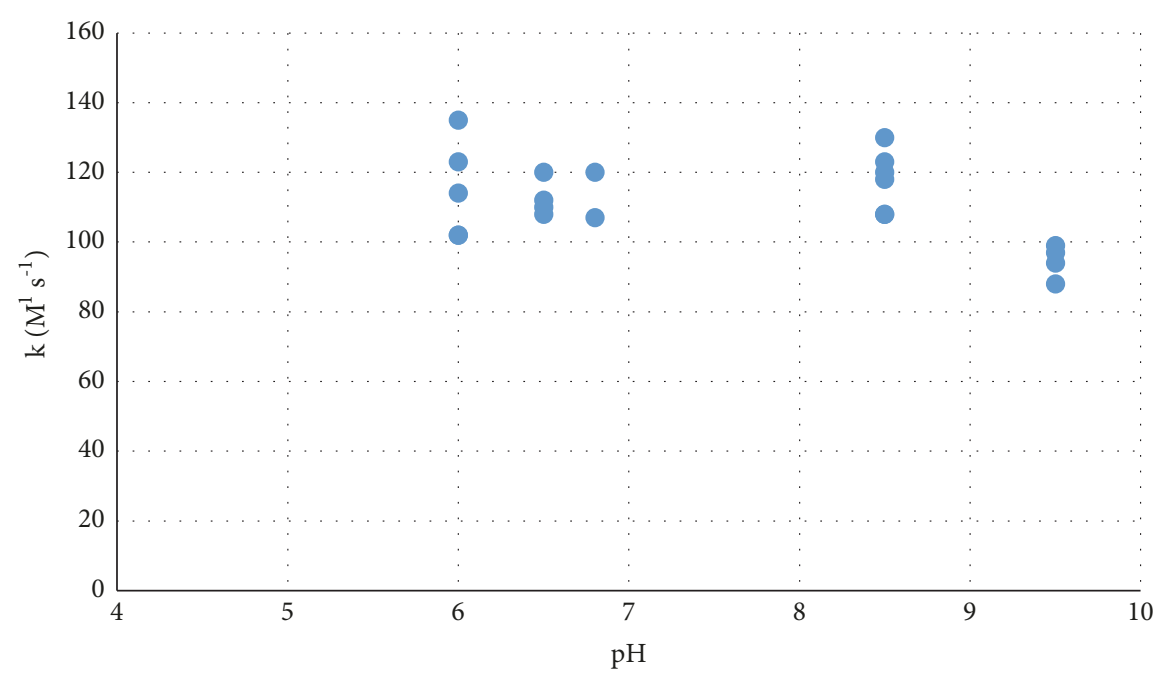

FIGURE 4: Variation of the MC-LA second order rate constant from $\mathrm{pH} 6$ to 9.5.

TABLE 4: Apparent rate constants determined by three methods at $25^{\circ} \mathrm{C}$ and $35^{\circ} \mathrm{C}$.

\begin{tabular}{lccccc}
\hline $\begin{array}{l}\text { Initial Concentration } \\
\text { Co }(\mu \mathrm{g} / \mathrm{L})\end{array}$ & $\begin{array}{c}\text { Permanganate } \\
\text { Concentration } \\
(\mathrm{ppm})\end{array}$ & $\begin{array}{c}\text { Temperature } \\
{ }^{\circ} \mathrm{C}\end{array}$ & $\begin{array}{c}\mathrm{k}_{\mathrm{PPIA}} \\
\mathrm{M}^{-1} \mathrm{sec}^{-1}\end{array}$ & $\begin{array}{c}\mathrm{k}_{\mathrm{MS}} \\
\mathrm{M}^{-1} \mathrm{sec}^{-1}\end{array}$ \\
\hline $50 \mathrm{MC}-\mathrm{LA}$ & 2.0 & $25 \pm 1$ & $116 \pm 4$ & $100 \pm 1.4$ & $\mathrm{k}_{\mathrm{ELISA}}$ \\
\hline $50 \mathrm{MC}-\mathrm{LA}$ & 2.0 & $35 \pm 1$ & $145 \pm 1.4$ & $134.5 \pm 10$ & $81.5 \pm 5$ \\
\hline
\end{tabular}

reduction in $\mathrm{k}$ when a cell lysate was added. More studies of this phenomenon with wild Microcystis strains should be performed before general conclusions are made, however. The M. viridis cells used in this experiment have been grown in culture for many years and do not exhibit colonial morphology; they primarily grow as single or double cells without a mucilaginous layer that is often observed in wild strains.

In general our observations are consistent with previous works that indicates that permanganate has a low reactivity with proteinaceous material and that, at moderate dosages, permanganate is unlikely to lyse cyanobacteria cells.

\subsection{Comparison between the Quantitation and Kinetics by} Adda-ELISA, PPIA, and LC/HRMS. Both the Adda-ELISA and PPIA can use a microplate reader format providing drinking water utilities a readily available on-site platform versus the LC/HRMS which is a costly instrument that needs a highly trained technician. Several natural water studies have compared the results from these three technologies [12-14] showing general agreement, but noting that the Adda-ELISA often reports higher concentrations than LC/MS, whereas the PPIA reports lower concentrations than the LC/MS. Limited studies have investigated Adda-ELISA and PPIA MC quantitation of waters that have undergone chemical oxidation with chlorine, ozone, and chloramines $[15,16]$. These results suggest that OPs from chlorination, ozone, and chloramines react with the Adda-ELISA antibody and the PPIA.

This work determined the apparent second order kinetics of the permanganate oxidation of MC-LA by Adda-ELISA,
PPIA, and LC/HRMS (Table 4 ) at $25 \pm 1 \mathrm{C}$ and $35.5 \pm 1 \mathrm{C}$. Since buffered DI water was used for this study, the permanganate demand is based on MC-LA and only MC-LA OP products are present. The $\mathrm{k}_{\mathrm{PPIA}}$ and $\mathrm{k}_{\mathrm{MS}}$ at both temperatures are very similar, while the $\mathrm{k}_{\text {ELISA }}$ has decreased by about $40 \%$. These data suggest that the MC-LA OPs from permanganate oxidation may be binding with the Adda-ELISA, but not the PPIA.

The permanganate OP pathways for MC-LR have been elucidated by Kim [21]. The primary paths were (1) oxidation at one of the three alkenes to make a hydroxyl ketone and (2) oxidative cleavage at the Adda diene or Mdha. OPs that may bind with Adda-ELISA include the oxidation products of the Mdha because the Adda remains intact and the oxidative cleavage of the C4-C5 alkene. This cleavage leaves the ring intact and produces (4S,5S, E)-5-methoxy-2,4-dimethyl-6-phenylhex-2-enal (MMPHA) and/or the (4S,5S,E)-5-methoxy-2,4-dimethyl-6-phenylhex2-enoic acid (MMPHH). MMPHH and MMPHA chemical structures are like Adda and may interfere with the AddaELISA.

The Adda-ELISA and PPIA results can be normalized by the corresponding LC/HRMS concentration (Figure 5). Similar to the observations reported by Guo et al. [15], the Adda-ELISA concentrations from time 0 to 480 seconds were about twice the concentration determined by the LC/HRMS. This is becuase MC-LA binds more efficiently to the antibody than MC-LR for which the calibration curve is generated. The time 0-minute sample is taken before the addition of permanganate for each experiment and diluted 20x (as are all samples) and serves as a control for each experimental 


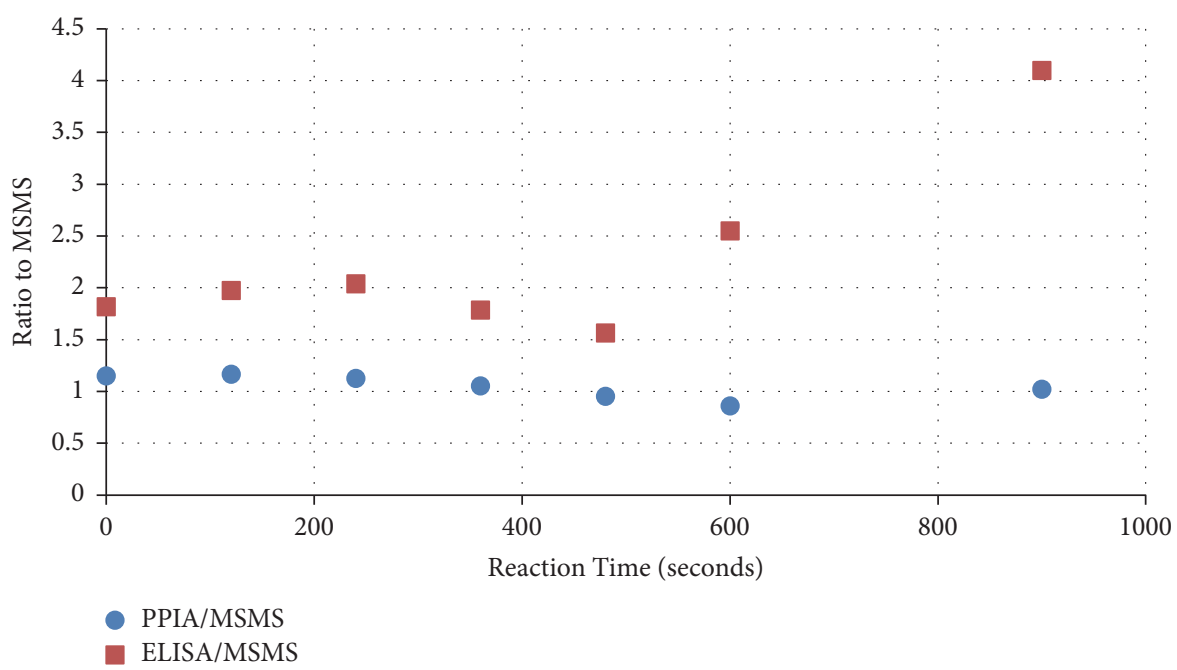

FIGURE 5: PPIA and Adda-ELISA normalized by LC/HRMS show that the ratio of the response of the Adda-ELISA increases as the reaction progresses.

run. The starting concentration of each experiment is $50 \mu \mathrm{g} / \mathrm{L}$ MC-LA and is determined independently by measurement of the MC-LA stock solution using UV spectroscopy. After 6-10 minutes, the MC-LA concentration determined by the Adda-ELISA is considerably larger than the LC/HRMS. The ratio between Adda-ELISA and LC/HRMS increased from 2 to 4 . This change in ratio reflects the change in the second order rate kinetics from concentrations determined by AddaELISA at $61 \mathrm{M}^{-1} \mathrm{sec}^{-1}$ versus the $100 \mathrm{M}^{-1} \mathrm{sec}^{-1}$ determined by LC/HRMS. These data suggest that, after 480 seconds, an $\mathrm{OP}(\mathrm{s})$ is at a high enough concentration to interfere with the Adda-ELISA. It is reasonable to suspect that the OP(s) has an intact Adda, MMPHA, or MMPHH.

The normalized PPIA results are close to 1.0 across the entire time interval. Often, researchers use the PPIA to predict MC toxicity. The MC concentrations and kinetic rate determined by PPIA matched the concentrations and kinetic rate determined by LC/HRMS (Table 4) within experimental error. The OPs formed do not appear to inhibit PP2A suggesting the OPs are unlikely to be toxic. Both the PP2A and Adda-ELISA bind to the Adda group in the MC, but they appear to react differently to the MC-LA OPs suggesting that the OPs reacting with Adda-ELISA do not inhibit protein phosphatase. These results suggest that, after permanganate oxidation, OPs can result in an Adda-ELISA false positive that may not be related to the toxicity of the water. It should be noted that the hepatotoxicity is also a function of the transport of MCs by the organic anion transporter (cell transmembrane protein) into liver cells. Consequently, future studies of OPs should include the use of cell-based assays to determine if OPs that do inhibit PP1 and PP2A are capable of entering liver cells and exhibiting toxicity.

3.3. Oxidation Products and Pathways. Over the last couple of decades, scientists have used mass spectrometry to determine the oxidation reaction pathways of MC-LR for a variety of oxidants. Understanding the pathway provides insight into the detoxification of MCs. Since the Adda group is the toxic center of the MC, the oxidation of Adda is critical in the detoxification/inactivation of MCs. However, biodegradation studies have shown that ring opening is another mechanism of detoxification [31,32]. Other studies have suggested that the kinetics determined by mass spectrometry (as shown above) do not provide the same kinetics as the Adda-ELISA $[15,16]$, yet no mechanism was provided to explain the disagreement. The most likely explanation is that the Adda remains intact after oxidation and binds to the antibody; it is also possible that the antibody is not that specific for Adda, and a piece(s) of the MC OP cross-reacts with the Adda antibody. Elucidation of the oxidation pathway(s) can provide insight as to the source of the false positives and promote design of better monitoring strategies.

Three previous studies proposed oxidation pathways for MC-LR with permanganate [20, 21, 26]. No previous study has elucidated the pathway for MC-LA. In the two earlier studies, dihydroxylation of the Adda and Mdha alkenes was the proposed product pathway. Dihydroxylation across the alkene is the permanganate alkaline (base) reaction frequently used by synthetic chemists. Jeong et al. [20] also suggested hydroxylation of the Adda benzene. Kim et al. [21] discounted these pathways as they did not detect the dihydroxy MC-LR intermediate products, nor did they think it is likely that permanganate would form hydroxylated benzene OPs given extremely slow rates of reaction for benzylic compounds and permanganate. Their pathway consists of 17 products formed via five reactions: (1) alkene to hydroxyketone; (2) alkene to aldehydes; (3) aldehyde to carboxylic acid; (4) amide to amine; or (5) carboxylic acid. They identified three classes of primary products: (1) hydroxyketone across one of the alkenes; (2) oxidation cleavage to form aldehydes; and/or (3) ketones. Secondary and tertiary oxidation proceeds via transformation of aldehydes to carboxylic acids, and hydrolysis of amide peptide bonds to an amine and carboxylic acid which opens the ring. Furthermore, their results implied that the $\alpha, \beta$ unsaturated carbonyl was less reactive than the diene to permanganate oxidation. 


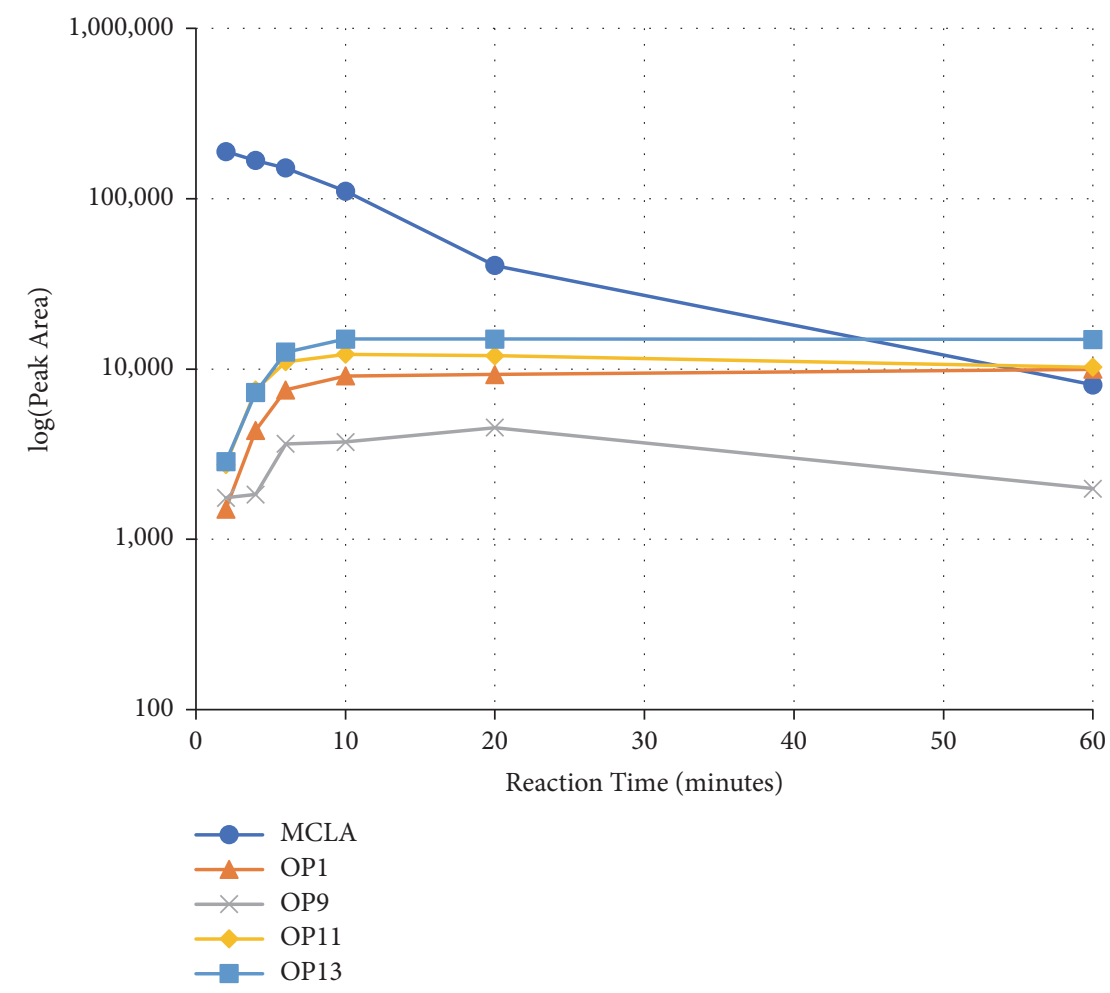

FiguRE 6: MC-LA major oxidation products formed via reaction with $2.0 \mathrm{ppm}$ permanganate at $22^{\circ} \mathrm{C}$.

In our pathway studies, $1000 \mu \mathrm{g} / \mathrm{L}$ MC-LA rather than $50 \mu \mathrm{g} / \mathrm{L}$ MC-LA was used with $2.0 \mathrm{mg} / \mathrm{L}$ permanganate to assure generation of sufficient concentration of minor OPs that could be detected by LC/HRMS. We also extended the reaction time from 40 to 60 minutes.

We identified eight major and several minor OPs of MCLA that are analogous to those identified in Kim et al's [21] work on MC-LR using similar LC/HRMS analysis. Our proposed oxidation pathways are analogous to the scheme developed by Kim et al. [21] for MC-LR oxidation with permanganate. Our labelling scheme follows theirs, albeit with the analogous formulas and masses representing MCLA OPs. The OP's chemical formula, mass, label, retention time, mass difference, and proposed structure are reported in Table 5. Three major OPs, i.e., one site of oxidation, were formed within 2 minutes: the oxidation of the Adda diene (Figure 1) to form hydroxy ketones and the oxidative cleavage of the C4-C5 alkene to form an aldehyde product. Since the three products appear at the first-time point ( $2 \mathrm{~min})$, it is not known if these OPs are produced in parallel or in series. These primary oxidation products undergo further oxidation. The oxidation reactions at the Mdha $\alpha, \beta$ unsaturated carbonyl seem to occur after the Adda diene reacts because they appear only at longer times.

The relative abundance of primary OPs from our permanganate MC-LA oxidation experiments is shown in Table 6 and Figure 6. The primary oxidation products we observed for the reaction of MC-LA with permanganate were generally analogous to those observed by Kim et al. [21] except for the aldehyde OP oxidized to the carboxylic acid. We observed
MC-LA analogs to OP11, hydroxyketones forming at sites A or B (Figure 1), and analogs for OP1 and OP9 forming by oxidative cleavage at sites A and C, respectively. Products OP1 and OP11 continued to increase in concentration over the course of the one-hour reaction, whereas OP9 peaked at 20 minutes and began to decline by 60 minutes. We did not observe dihydroxy MC-LA $\left(\mathrm{C}_{46} \mathrm{H}_{69} \mathrm{~N}_{7} \mathrm{O}_{14} ;[\mathrm{M}+\mathrm{H}]^{+}=\right.$ 944.49747) or the aldehyde formed by oxidative cleavage at site B. This study, using MC-LA and all previous pathway studies with MC-LR, agree that OP1 analogs form rapidly and are the major product. Furthermore, this aldehyde OP should be nontoxic and is unlikely to react with the Adda-ELISA or the PPIA, given that the Adda is cleaved.

Secondary OPs, OP10 and OP13, appear at two minutes and OP13 is the major OP of MC-LA. Both OPs are formed by hydrolysis of an amide bond. If the HRMS response is relatively constant across the products, OP13 is the most abundant OP produced over the course of our one-hour reaction time. Kim et al. [21] observed the same behavior. An interesting deviation from Kim et al's observations is that we do not observe OP3, OP4, and OP7 within one hour [21]. The secondary OPs react via amide hydrolysis and result in the formation of carboxylic acids and opening of the peptide ring. In the Kim et al's study [21], OP7 (formed via oxidation of the aldehyde from precursor OP3 or OP6) was a major product along with primary OP1 and OP11. The minor products in Kim et al's study were analogous to OP3, OP4, OP9, OP10, and OP17 [21]. Similarly, we did not observe OP3, OP4, and OP17 while we did see OP5 and OP7. Our minor products were OP2, OP8, OP10, OP12, and OP15. OP16 and OP8 can be 
TABLE 5: Description of MC-LA permanganate OP.

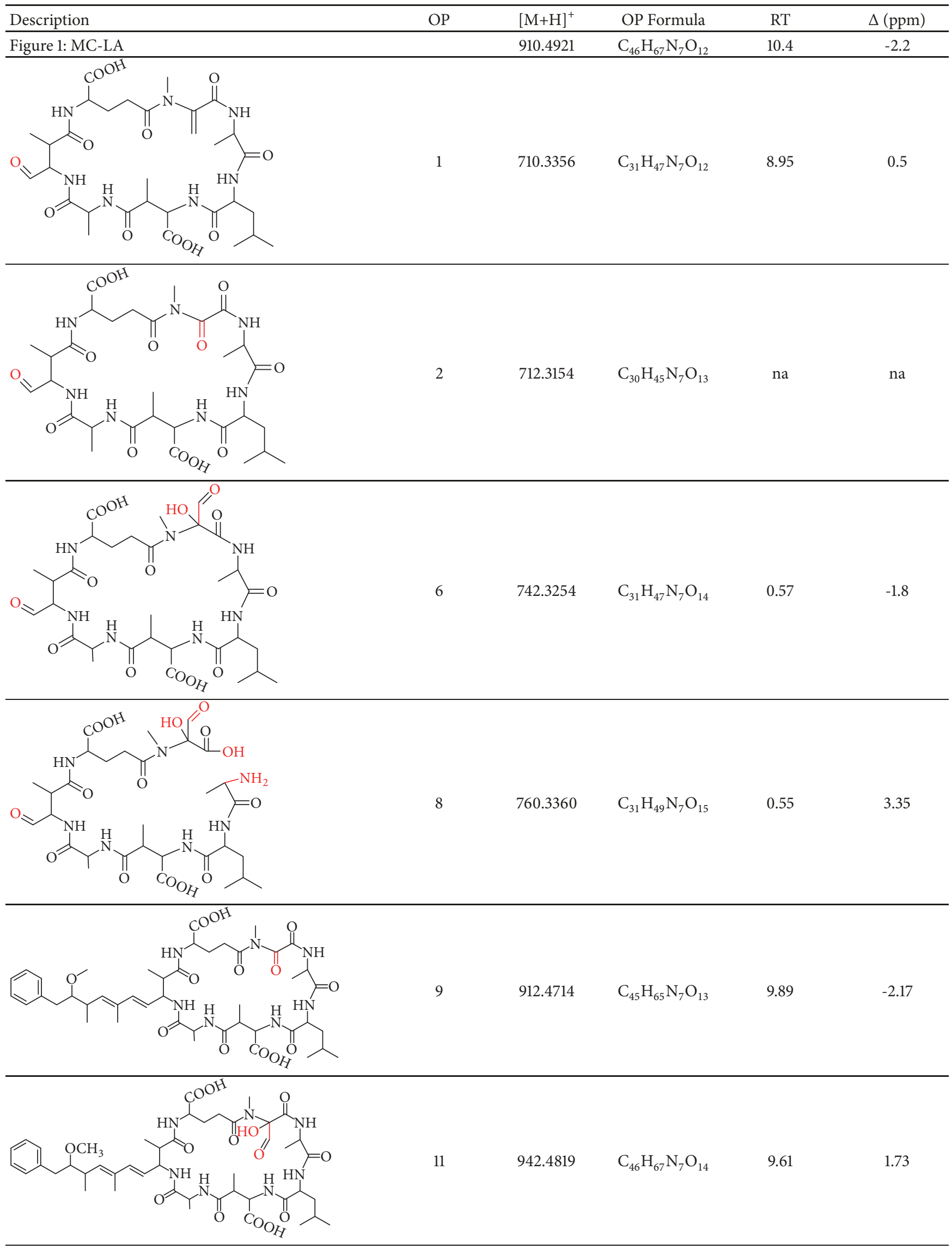


TABLE 5: Continued.

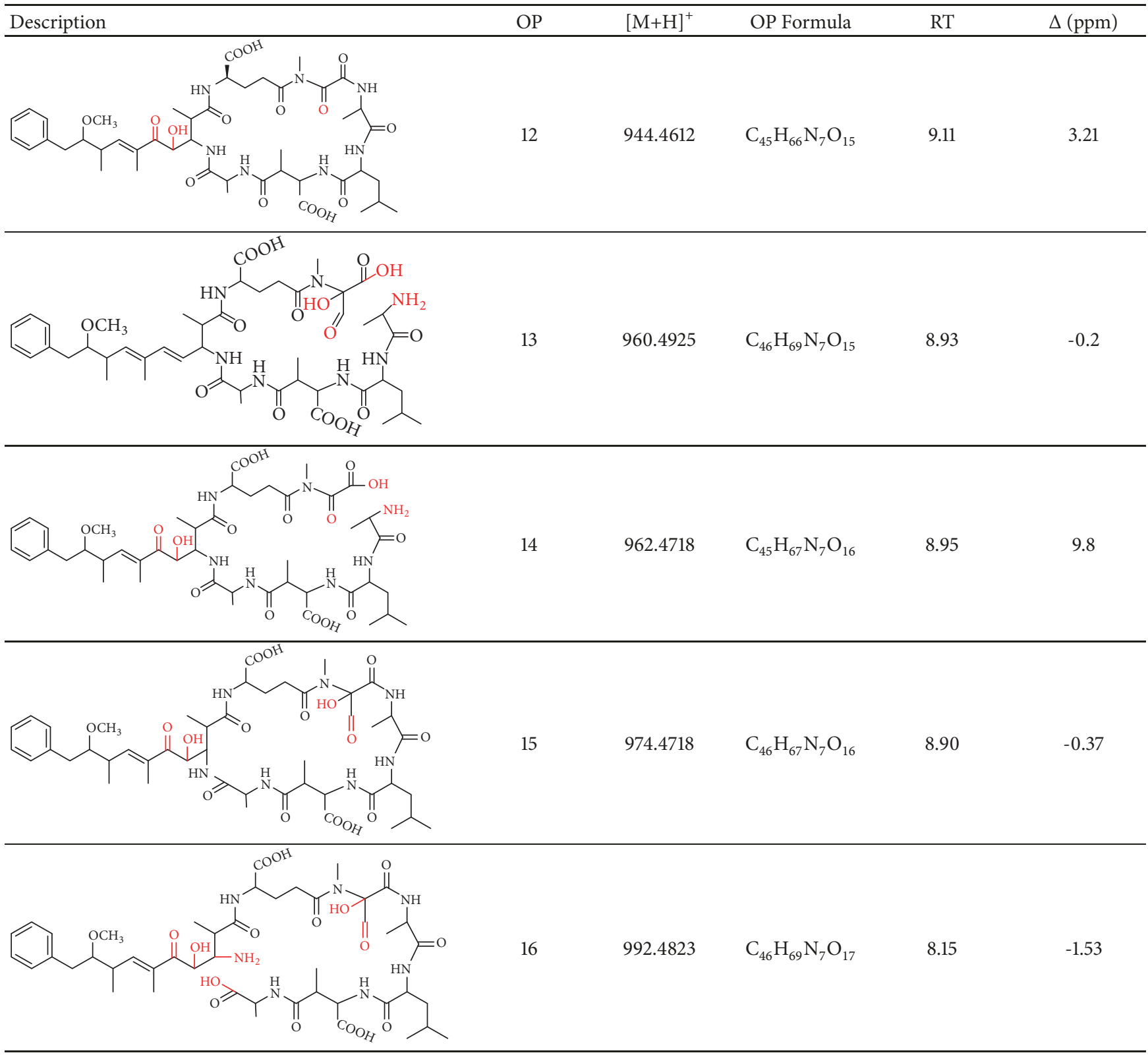

referred to as a tertiary OPs because they have been oxidized twice and hydrolyzed once. Oxidative cleavage to carbonyls and oxidation to hydroxyketone at the three alkenes are the first reactions to take place. We can infer that hydrolysis of the amide peptide bond is fast only after the initial oxidation of the alkene.

From these observations we can infer that the major pathways for MC-LA transformation are $\mathrm{MC}-\mathrm{LA} \longrightarrow \mathrm{OP} 11 \longrightarrow$ $\mathrm{OP} 13 \longrightarrow \mathrm{P} 16, \mathrm{MC}-\mathrm{LA} \longrightarrow \mathrm{OP} 1=>\mathrm{P} 6$, and $\mathrm{MC}-\mathrm{LA} \longrightarrow \mathrm{OP} 9=>$ OP12. Many OPs have several possible structural isomers as well as stereoisomers. OP9 and OP10 have intact Adda and are likely to be toxic or interfere with the Adda-ELISA kit. They are not the major products, however, for MC-LA. OP9 is produced in relatively modest amounts relative to OP1, OP11, and OP13 but is not the likely interferent with the Adda-ELISA because it is converted to OP12. OP10 is likely to interfere with Adda-ELISA but is produced in minor amounts. Preliminary fragmentation studies confirm that P10 has an intact Adda. OP11 and OP13 have four possible isomers. OP11 and OP13 (Figure 7) with intact Adda are likely to interact with the Adda-ELISA. OP13 is likely to exhibit interaction with the Adda-ELISA but, because of the open ring, will not inhibit PP1 or PP2a. This is the most likely candidate for the interference with the Adda-ELISA. Subsequent work will attempt to isolate OP11 and P13 and test for interference with the Adda-ELISA and toxicity.

\section{Conclusions}

The results presented provide a better understanding of how permanganate reduces MC toxicity and identifies several practical implications. Chemical oxidation of MC with 2.0 


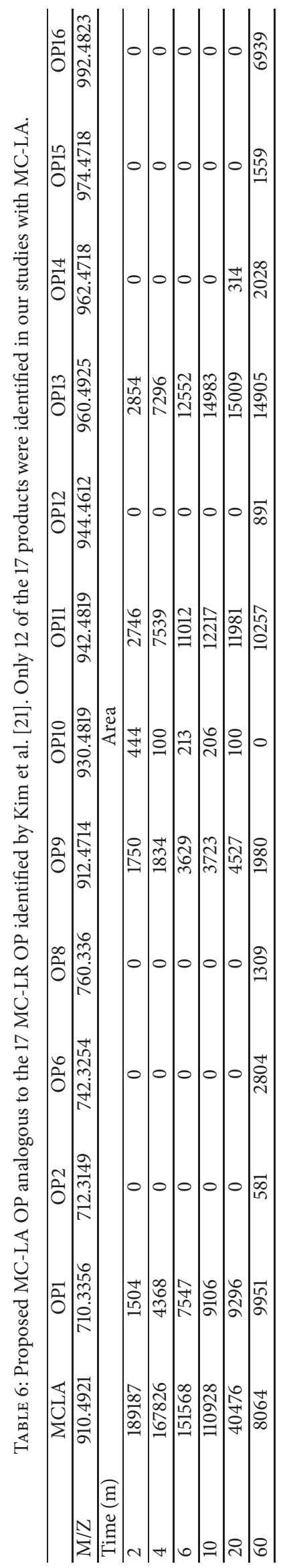




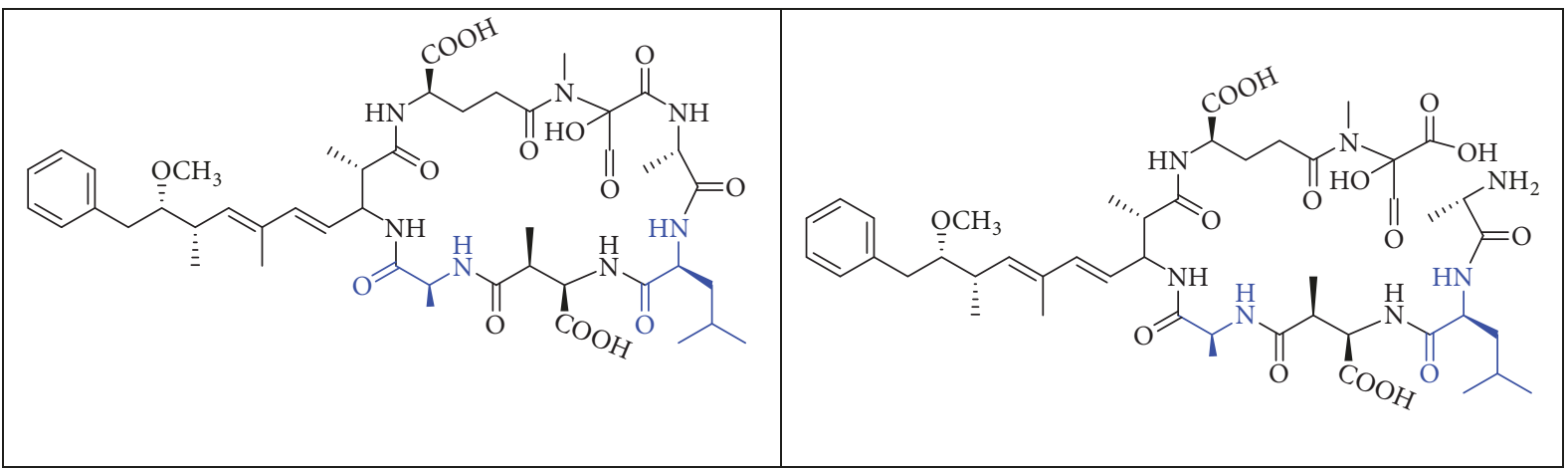

FIgURE 7: Two OP isomers, OP11 and OP13, with intact Adda that are likely interferents. Note that OP13 is an open ring.

$\mathrm{mg} / \mathrm{L}$ permanganate with sufficient contact times can be an effective first barrier for the more hydrophilic MCs, MC$\mathrm{RR}$, and MC-LR that oxidize rapidly. We determined that MC-LA has much slower kinetics than previously reported. Regional difference in bloom ecology gives rise to different congener profiles. Identification of blooms dominated by MC-LA is essential to manage the treatment process. We tested permanganate oxidation with Lake Erie water and different levels of cells. The NOM and cells did not change the rate constants and confirmed the selectivity of the permanganate. Furthermore, there was no evidence that permanganate lysed the cells at $2.0 \mathrm{mg} / \mathrm{L}$. We also showed that OP can interfere with the Adda-ELISA whereas the PPIA kit tracks the HRMS well. Furthermore, inhibition of PP2A is significantly reduced, implying toxicity is also reduced. The most likely OP for interfering with the AddaELISA kit is OP13, an open ring OP with intact Adda or the MMPHA/MMPHH. We also show that MC-LR and MCLA congeners give rise to different ratios of analogous OPs and that further research is necessary regarding the toxicity of individual OPs. One significant area of concern is the effect of higher $\mathrm{pH}$. Most $\mathrm{cHAB}$ events cause the $\mathrm{pH}$ of the source water to rise and it is not uncommon to observe source water with pHs between 8 and 9.5. It is possible that $\mathrm{pH}$ at the higher range may slow the reaction and produce a different set of OPs that could enhance interference and toxicity.

\section{Data Availability}

The data used to support the findings of this study are available from the corresponding author upon request.

\section{Conflicts of Interest}

The authors declare that they have no conflicts of interest.

\section{Acknowledgments}

We would like to thank the following organizations: Oakland University Summer Research in Chemistry, Water Research Foundation \#4647, and CURES (P30 ES020957). We would like to acknowledge Dr. Johnna Birbeck, Lumigen Instrument
Center, Wayne State University, for her mass spectrometry expertise.

\section{References}

[1] J. M. O’Neil, T. W. Davis, M. A. Burford, and C. J. Gobler, “The rise of harmful cyanobacteria blooms: The potential roles of eutrophication and climate change," Harmful Algae, vol. 14, pp. 313-334, 2012.

[2] H. W. Paerl and V. J. Paul, "Climate change: links to global expansion of harmful cyanobacteria," Water Research, vol. 46, no. 5, pp. 1349-1363, 2012.

[3] J. A. Westrick and D. Szlag, "A cyanotoxin primer for drinking water professionals," Journal - American Water Works Association, vol. 110, no. 8, pp. E1-E16, 2018.

[4] X. He, Y.-L. Liu, A. Conklin et al., "Toxic cyanobacteria and drinking water: Impacts, detection, and treatment," Harmful Algae, vol. 54, pp. 174-193, 2016.

[5] J. R. Schmidt, S. W. Wilhelm, and G. L. Boyer, "The fate of microcystins in the environment and challenges for monitoring," Toxins, vol. 6, no. 12, pp. 3354-3387, 2014.

[6] K. A. Loftin, J. L. Graham, E. D. Hilborn et al., "Cyanotoxins in inland lakes of the United States: Occurrence and potential recreational health risks in the EPA National Lakes Assessment 2007," Harmful Algae, vol. 56, pp. 77-90, 2016.

[7] L. Ho, G. Onstad, U. V. Gunten, S. Rinck-Pfeiffer, K. Craig, and G. Newcombe, "Differences in the chlorine reactivity of four microcystin analogues," Water Research, vol. 40, no. 6, pp. 12001209, 2006.

[8] World Health Organization, Cyanobacterial Toxins: Microcystin-LR in Drinking Water; Cyanobacterial Toxins: Microcystin$L R$ in Drinking Water; WHO/SDE/WSH/03.04/57, World Health Organization, Geneva, Switzerland, 2003.

[9] US EPA, Drinking Water Health Advisory for the Cyanobacterial Microcystin Toxins, EPA-820R15101. Office of Water, 2015.

[10] US EPA, "Method 546: Determination to total microcystins and nodularins in drinking water and ambient water by Addaenzyme-linked immunosorbent assay," https://www.epa.gov/ sites/production/files/2016-09/documents/method-546-determination-total-microcystins-nodularins-drinking-water-ambient-water-adda-enzyme-linked-immunosorbent-assay.pdf, 2018.

[11] T. Triantis, K. Tsimeli, T. Kaloudis, N. Thanassoulias, E. Lytras, and A. Hiskia, "Development of an integrated laboratory system 
for the monitoring of cyanotoxins in surface and drinking waters," Toxicon, vol. 55, no. 5, pp. 979-989, 2010.

[12] T. Kaloudis, S.-K. Zervou, K. Tsimeli, T. M. Triantis, T. Fotiou, and A. Hiskia, "Determination of microcystins and nodularin (cyanobacterial toxins) in water by LC-MS/MS. Monitoring of Lake Marathonas, a water reservoir of Athens, Greece," Journal of Hazardous Materials, vol. 263, pp. 105-115, 2013.

[13] A. J. Foss and M. T. Aubel, "Using the MMPB technique to confirm microcystin concentrations in water measured by ELISA and HPLC (UV, MS, MS/MS)," Toxicon, vol. 104, pp. 91101, 2015.

[14] D. O. Mountfort, P. Holland, and J. Sprosen, "Method for detecting classes of microcystins by combination of protein phosphatase inhibition assay and ELISA: Comparison with LCMS,” Toxicon, vol. 45, no. 2, pp. 199-206, 2005.

[15] Y. C. Guo, A. K. Lee, R. S. Yates, S. Liang, and P. A. Rochelle, "Analysis of microcystins in drinking water by ELISA and LC/MS/MS," Journal - American Water Works Association, vol. 109, no. 3, pp. 13-25, 2017.

[16] X. He, B. D. Stanford, C. Adams, E. J. Rosenfeldt, and E. C. Wert, "Varied influence of microcystin structural difference on ELISA cross-reactivity and chlorination efficiency of congener mixtures," Water Research, vol. 126, pp. 515-523, 2017.

[17] J. Fan, R. Daly, P. Hobson, L. Ho, and J. Brookes, "Impact of potassium permanganate on cyanobacterial cell integrity and toxin release and degradation," Chemosphere, vol. 92, no. 5, pp. 529-534, 2013.

[18] J. Fan, L. Ho, P. Hobson, and J. Brookes, "Evaluating the effectiveness of copper sulphate, chlorine, potassium permanganate, hydrogen peroxide and ozone on cyanobacterial cell integrity," Water Research, vol. 47, no. 14, pp. 5153-5164, 2013.

[19] H. Ou, N. Gao, C. Wei, Y. Deng, and J. Qiao, "Immediate and long-term impacts of potassium permanganate on photosynthetic activity, survival and microcystin-LR release risk of Microcystis aeruginosa," Journal of Hazardous Materials, vol. 219-220, pp. 267-275, 2012.

[20] B. Jeong, M.-S. Oh, H.-M. Park et al., "Elimination of microcystin-LR and residual Mn species using permanganate and powder activated carbon: Oxidation products and pathways," Water Research, vol. 114, pp. 189-199, 2017.

[21] M. S. Kim, H.-J. Lee, K.-M. Lee, J. Seo, and C. Lee, "Oxidation of microcystins by permanganate: $\mathrm{PH}$ and temperaturedependent kinetics, effect of DOM characteristics, and oxidation mechanism revisited," Environmental Science \& Technology, vol. 52, no. 12, pp. 7054-7063, 2018.

[22] J. Chang, Z.-L. Chen, Z. Wang et al., “Ozonation degradation of microcystin-LR in aqueous solution: Intermediates, byproducts and pathways," Water Research, vol. 63, pp. 52-61, 2014.

[23] H. Miao, F. Qin, G. Tao et al., "Detoxification and S59 degradation of microcystin-LR and -RR by ozonation," Chemosphere, vol. 79, no. 4, pp. 355-361, 2010.

[24] Y. Zhang, Y. Shao, N. Gao, W. Chu, and Z. Sun, "Removal of microcystin-LR by free chlorine: Identify of transformation products and disinfection by-products formation," Chemical Engineering Journal, vol. 287, pp. 189-195, 2016.

[25] ISO 2019, "Water quality, -Determination of microcystins Method using solid phase extraction (SPE) and high performance liquid chromatography (HPLC) with ultraviolet (UV) detection," 2005.

[26] J. Ding, H. Shi, T. Timmons, and C. Adams, "Release and removal of microcystins from microcystis during oxidative-, physical-, and UV-based disinfection," Journal of Environmental Engineering, vol. 136, no. 1, pp. 2-11, 2010.

[27] E. Rodríguez, M. E. Majado, J. Meriluoto, and J. L. Acero, "Oxidation of microcystins by permanganate: reaction kinetics and implications for water treatment," Water Research, vol. 41, no. 1, pp. 102-110, 2007.

[28] X. Chen, B. Xiao, J. Liu, T. Fang, and X. Xu, "Kinetics of the oxidation of MCRR by potassium permanganate," Toxicon, vol. 45, no. 7, pp. 911-917, 2005.

[29] B. D. Stanford, C. Adams, E. J. Rosenfeldt, E. Arevalo, and A. Reinert, "CyanoTOX: Tools for managing cyanotoxins in drinking water treatment with chemical oxidants," Journal American Water Works Association, vol. 108, no. 12, pp. 41-46, 2016.

[30] R. M. Cory, T. W. Davis, G. J. Dick et al., "Seasonal dynamics in dissolved organic matter, hydrogen peroxide, and cyanobacterial bloom in Lake Erie," Frontiers inMarine Science, vol. 3, article no. 54, pp. 1-17, 2016.

[31] D. G. Bourne, G. J. Jones, R. L. Blakeley, A. Jones, A. P. Negri, and P. Riddles, "Enzymatic pathway for the bacterial degradation of the cyanobacterial cyclic peptide toxin microcystin LR," Applied and Environmental Microbiology, vol. 62, no. 11, pp. 4086-4094, 1996.

[32] B. M. Gulledge, J. B. Aggen, and A. R. Chamberlin, "Linearized and truncated microcystin analogues as inhibitors of protein phosphatases 1 and 2A," Bioorganic \& Medicinal Chemistry Letters, vol. 13, no. 17, pp. 2903-2906, 2003. 

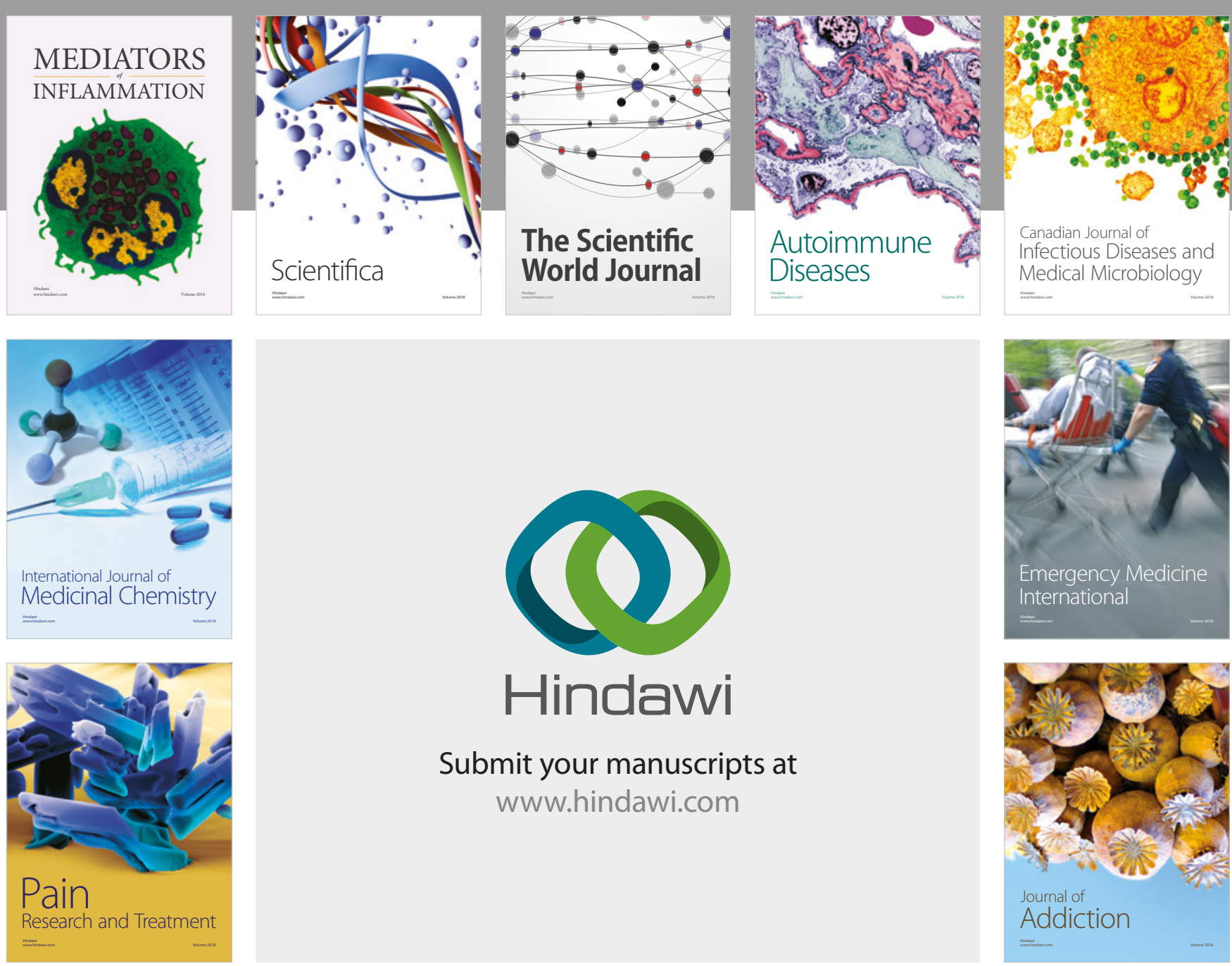

Canadian Journal of
Infectious Diseases and Medical Microbiology

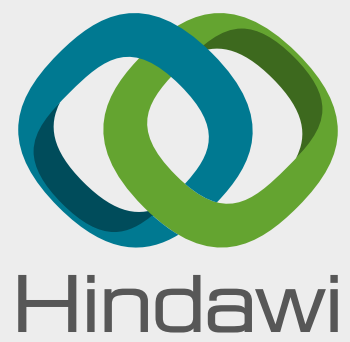

Submit your manuscripts at

www.hindawi.com
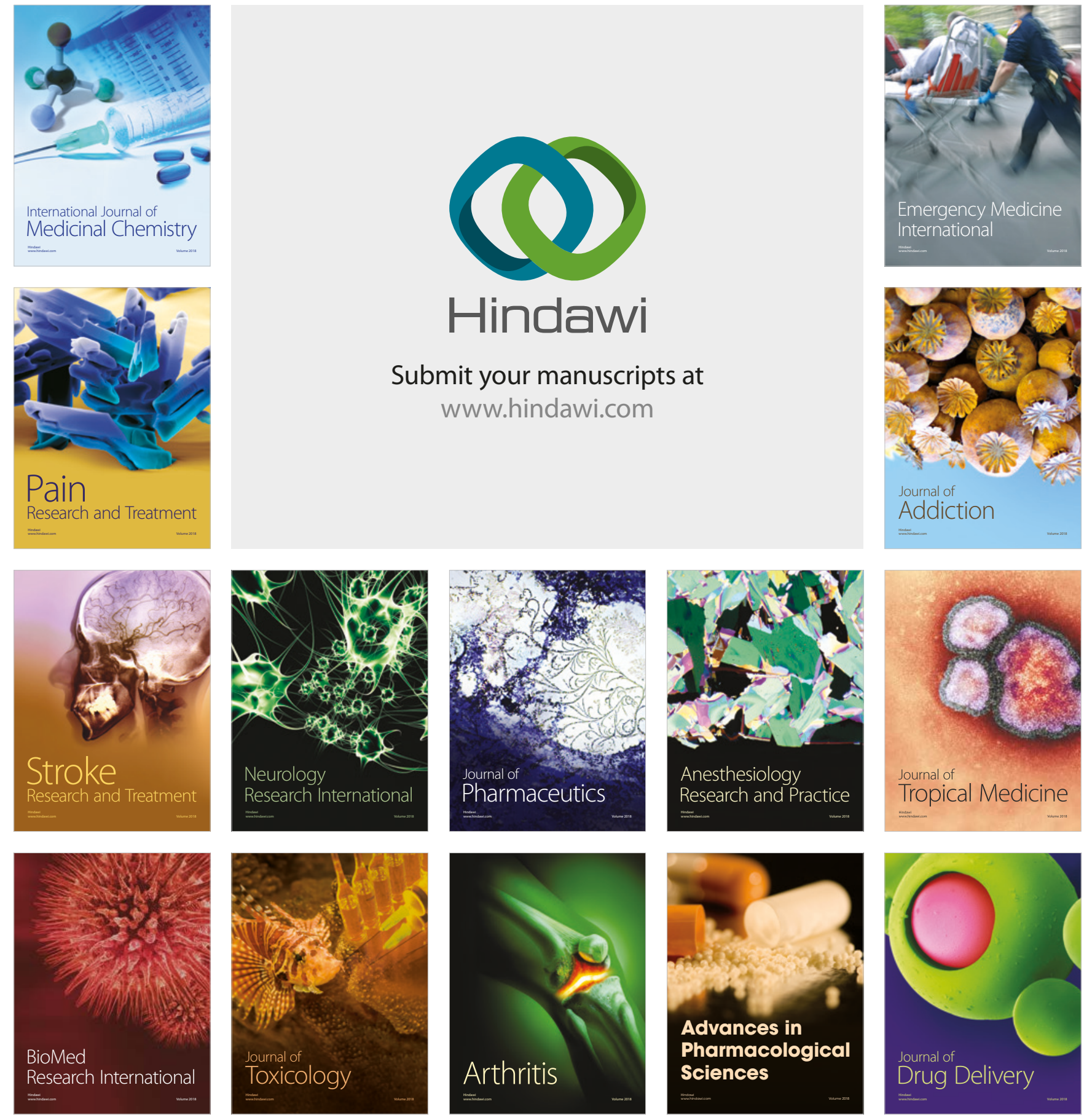